\title{
Silicon preparation derived from geothermal silica by reduction using magnesium
}

\author{
Silviana Silviana ${ }^{1}$, Amar Ma'ruf ${ }^{2}$ \\ ${ }^{1}$ Department of Chemical Engineering, Faculty of Engineering, Universitas Diponegoro, Semarang, Indonesia \\ ${ }^{2}$ Department Chemical Engineering, Faculty of Engineering, Universitas Diponegoro, Semarang, Indonesia \\ * Corresponding Email: silviana@che.undip.ac.id
}

\begin{abstract}
Geothermal silica denotes as a potential source of silica due to high content of silica. Silica can be converted to be silicon through magnesiothermal reduction. The objectives of paper are to obtain the optimum ratio of $\mathrm{Mg}$ to $\mathrm{SiO}_{2}$, and to obtain acetic acid concentration in the second leaching of the silicon. At beginning, purification of geothermal silica was carried out through acid leaching by $20 \%$ of hydrosulfuric acid $\left(\mathrm{H}_{2} \mathrm{SO}_{4}\right)$ with silica content of $96.3 \mathrm{wt} \%$. Silicon conversion had been performed used magnesiothermic reduction at 650 $\mathrm{oC}$ for 7 hours. The mole ratio of $\mathrm{Mg}$ to $\mathrm{SiO}_{2}$ used 1.6:1, 2:1, and 2.5:1. The acid leaching process used $\mathrm{HCl}(3 \mathrm{~N})$ at $60{ }^{\circ} \mathrm{C}$ for 1 hour and utilized HFof $(5 \mathrm{~N})$ with varied acetic acid concentration for 1 hour at $70{ }^{\circ} \mathrm{C}(25,35,45,50$, and $60 \%$ ww). Afterward, the results were confirmed by characterization of the silicon with XRF analsys. Silicon yield was achieved at $77.1 \mathrm{wt} \%$ with $91.4 \mathrm{wt} \%$ of purity at first acid leaching. This results have been generated by use of $\mathrm{Mg}$ to $\mathrm{SiO}_{2}$ ratio at 2:1 and leached out by $\mathrm{HCl} 3 \mathrm{~N}$. However, at second acid leaching with HF-acetic acid mixture released the purity of silicon at $93.9 \mathrm{wt} \%$. Silicon from geothermal silica can replace the use of graphite as anodes of lithium ion batteries.
\end{abstract}

Key words : geothermal silica, magnesiothermic reduction, acid leaching.

\section{INTRODUCTION}

Natural silica is mostly in the soil in the form of silicic acid, which is then absorbed by plants. Some plants that are known as natural silica sources include rice husks, rice straw, sugar cane and bamboo leaves [1]. Silica sources have been widely observed previously, such as sourced from rice husk (8.7-12.1 wt\%) [2], fly ash (53.84 wt\%) [3], bamboo leaves (75.9-82.86 wt\%) [4], and geothermal solid waste has a large silica content of $88,45 \mathrm{wt} \%$ [1]. Geothermal solid waste from geothermal plant in Dieng was selected because it consists of a relatively high silica oxide content [1]. In the process of geothermal processing into electrical energy, solid waste is produced in the form of slurry. Slurry contains dissolved iron (Fe), dissolved manganese (Mn), zinc, mercury, lead, arsenic, cyanide, barium, boron, cadmium, chromium, copper, lead, mercury, selenium, silver, zinc and silica. Productivity of geothermal liquid waste attained 10 tons/day with solid waste of $10 \mathrm{wt} \%$ [1].

Silica has been utilized for various purposes such as an organic compound adsorbent [5], as nano-silica for the food industry, packaging, sensors, carrier nutrients [6]; a mixture of cement [7], and environmentally friendly precursors [8]. Other uses can be formed as silicon as electronic equipment, photovoltaics, lithium battery anodes [9], solar-grade [10] metallurgy, semiconductor industry and silicon synthesis derived from bamboo leaf silica [4]. Utilization of silica as a raw material storage energy is very interesting nowadays. However, firstly silica must be converted into silicon in order to serve as anode storage energy. Silicon (Si) has a high potential capacity [11]. Si capacity occupies ten times higher than conventional graphite anode [12].

Silicon has the large storage capacity compared to other material, $4200 \mathrm{mAh} / \mathrm{g}$ [13], [14]. Silicon is relatively unaffordable, safe, and has a relatively low disposal potential $(\approx 0.37 \mathrm{~V}$ vs $\mathrm{Li}+/ \mathrm{Li}) ;[15]$. Anode from silicon has large gravimetric and volumetric capacities [14]). Silicon has become an alternative material that is widely used as a lithium battery anode [16]; therefore silicon has the potential to replace graphite anodes.

Silica conversion method into silicon consists of three main stages, i.e. silica purification, silica conversion, and silicone purification. The process of silica purification is aimed to eliminate silica impurities before being converted to silicon. According to research by [4] focusing on the conversion of bamboo leaves-based silica into silicon from bamboo leaves, Si electrode capacity was still low about $0,002 \mathrm{mAh}$ for 22 cycles. The purity of silica acid leaching results only reached $93.6 \%$ and silicon conversion results obtained low too, i.e $61.2 \%$.It was resulted the leached silica still contain metal 
impurities. The presence of impurities affect on the nature and quality of treated silica [4]. Purification solid waste of geothermal by first acid leaching released silica content of $95.6 \%$ with main impurities contentration of $\mathrm{Ca}(1.7 \%)$ and Fe (1.51\%) (Silviana, et al., 2017). Several acids are used, such as $\mathrm{HF}, \mathrm{H}_{3} \mathrm{PO}_{4}, \mathrm{H}_{2} \mathrm{C}_{2} \mathrm{O}_{4}$, and $\mathrm{H}_{2} \mathrm{SO}_{4}[17] ; \mathrm{HNO}_{3}, \mathrm{HCl}[18]$ for investigating mainly effects on the removal of iron $(\mathrm{Fe})$. The next process is the conversion of silica into silicon. In this process there are several conventional methods, such as the carbothermic, aluminothermic, calsiothermic and magnesiothermic reduction methods [4]. In the silicon carbotermic reduction process obtained from silica reduction in the presence of carbon at high temperatures up to $2000^{\circ} \mathrm{C}$ this method requires high energy [19]. The aluminothermic reduction method uses aluminum as a reducing agent because aluminum can reduce silica to silicon [18]. However, in this process the formation of mullite and alumina as an aluminothermic reduction reduction product may not be suitable for acid leaching [18]. Whereas, the calciothermic reduction method is similar to aluminothermic reduction [19],[20] reported the conversion of silica $\left(\mathrm{SiO}_{2}\right)$ into silicon through the magnesiothermic reduction method. This method has been modified using magnesium $(\mathrm{Mg})$ as a reducing agent. Magnesium can reduce the pyrolysis temperature to $650^{\circ} \mathrm{C}$ [19]. After conversion, silicone results from the reaction should be purified again using acid leaching method to obtain high purity silicon [19].

In the conversion of silica, combustion conditions at the magnesiothermic reduction stage also need to be observed. The length time, temperature, and $\mathrm{Mg} / \mathrm{SiO}_{2}$ ratio produce a by-product of $\mathrm{Mg}_{2} \mathrm{Si}$ [10]. The research of acid leaching process modification and observation of optimum magnesiothermic reduction conditions from this geothermal silica was required to be carried out. The following reactions can be seen in Eq. 1 to 3 [12]:

$$
2 \mathrm{Mg}_{(\mathrm{g})}+\mathrm{SiO}_{2(\mathrm{~s})} \longrightarrow 2 \mathrm{MgO}_{(\mathrm{s})}+\mathrm{Si}_{(\mathrm{s})}
$$

If excess Mg:

$$
2 \mathrm{Mg}_{(\mathrm{g})}+\mathrm{Si}_{(\mathrm{s})} \longrightarrow \mathrm{Mg}_{2} \mathrm{Si}_{(\mathrm{s})}
$$

The other reaction (Barati et al., 2011):

$$
2 \mathrm{MgO}_{(\mathrm{s})}+\mathrm{SiO}_{2} \longrightarrow \mathrm{Mg}_{2} \mathrm{SiO}_{4(\mathrm{~s})}
$$

If there is an excess of $\mathrm{Mg}$, there will be a reaction to the formation of magnesium silicide $\left(\mathrm{Mg}_{2} \mathrm{Si}\right)$ which can reduce $\mathrm{Si}$ yield and increase magnesium demand [10]. In fact, magnesium silicide is thermodynamically insecure within the sight of $\mathrm{SiO}_{2}$ because kinetic restrictions that anticipate total silica reduction [10]. The presence of non-converted silica cannot be avoided in the magnesiothermic reduction reaction. In the process of magnesiothermic reduction reaction, magnesium gas reacts from the surface to the silica core. The formation of a silicon layer prevents magnesium gas from penetrating the silica core (Bao, et al., 2007). Silica that has not been converted is assumed to react with $\mathrm{MgO}$ compounds that have been formed to produce $\mathrm{Mg}_{2} \mathrm{SiO}_{4}$ [10].

The unreacted silica, $\mathrm{MgO}, \mathrm{Mg}_{2} \mathrm{SiO}_{4}$, and $\mathrm{Mg}_{2} \mathrm{Si}$ need to be removed to get high purity of Silica [10]. There are two leaching stage, the first stage is use hydrochloric acid inorder to remove excess magnesium. $\mathrm{MgO}$ removal is strongly influenced by concentration of acid, temperature and particle size while the effect of solid composition is not significant [20]. Detailed research on dissolving $\mathrm{MgO}$ using hydrochloric acid $(\mathrm{HCl})$ has been observed previously [10]. The effects of $\mathrm{HCl}$ concentration were studied by kinetics of Magnesium extraction. Second acid leaching with $\mathrm{HF}$ and $\mathrm{CH}_{3} \mathrm{COOH}$ done to remove the unreduced $\mathrm{SiO}_{2}$ and $\mathrm{Mg}_{2} \mathrm{SiO}_{4}$ [10]. Lai et al. [21], in their study of increased leaching of metallurgical grade silicon acids containing hydrogen peroxide as an oxidizing agent, found that the lower concentrations of HF would be needed to achieving high silicon impurities. However, acetic acid $\left(\mathrm{CH}_{3} \mathrm{COOH}\right)$ was added to improve the moisten behavior to get better particles, due to diminished surface tension of solution [10]. Some research [22], [23] related to current work, can be further explored for future research.

This research was aimed to determine the optimum ratio of $\mathrm{Mg}$ to $\mathrm{SiO}_{2}$ through silicon conversion of geothermal silica by magnesiothermic reduction, to observe the optimum of acetic acid concentration in the second leaching of the silicon.

\section{MATERIALS AND METHOD}

\subsection{Preparation of raw materials}

Geothermal waste raw materials was put as much as 200 grams and dried with an oven at a temperature of $100^{\circ} \mathrm{C}$ to remove water content. Then, the dried silica was reduced by High Energy Milling (HEM) Ellips-3D for 10 minutes (time on 300s / time off 300s) and sieved to obtain 325 mesh silica sample. Afterwards, the preparation results were analyzed using XRF instrument to obtain yield of silica.

\subsection{Acid leaching}

The acid leaching followed the method of [17] with slight modification. This process taken place by pouring $500 \mathrm{~mL}$ of $20 \%$ hydro sulfuric acid into 125 grams of the geothermal waste sample at three-neck flask. This mixture was refluxed for 1 hour 45 minutes (as modification) at $100^{\circ} \mathrm{C}$ with 
constant stirring, then filtered and then the residue was washed with distilled water until it has neutral properties and checked with a pH meter. Afterwards, the residue was dried at the oven for 10 minutes at $100{ }^{\circ} \mathrm{C}$. The dried powder was analyzed XRF again prior to be continued in the sol-gel process.

\subsection{Sol-gel}

Sol-gel method referred to previously research [4]. In this method, $600 \mathrm{~mL} \mathrm{NaOH}$ concentration of $2 \mathrm{~N}$ was added to 100 grams of the dried silica from the acid leaching process. This solution was mixed by a magnetic stirrer with a speed of $150 \mathrm{rpm}$ and a temperature between $95{ }^{\circ} \mathrm{C}$ with a time of \pm 1 hour. Afterwards, the solution was filtered to separation filtrate and residue. The filtrate was mixed with $\mathrm{HCl} 1 \mathrm{~N}$ with constant stirring until $\mathrm{pH}$ of 7 to form gel. Afterward, the gel were left for 18 hours and washed with distilled water.

\subsection{Magnesiothermic reduction}

Silica samples that have passed the refining process are placed on a porcelain cup. The reduction step occurs when magnesium was added to the powder phase in a ratio of $\mathrm{Mg}$ to $\mathrm{SiO}_{2}$ 2:1 [24]. This mixture is carried out by the solid state method so that it becomes homogeneous and then refined at $650{ }^{\circ} \mathrm{C}$ for 7 hours at ratio of $\mathrm{Mg}$ to $\mathrm{SiO}_{2}$ at 2:1 [21]. In this paper, the variables of ratio $\mathrm{Mg}$ to $\mathrm{SiO}_{2}$ was conducted at 1.6:1 and 2.5:1. The redacted silica samples (unpurified silicon) were analyzed by XRF.

\subsection{Purification of silicon}

According to[10] the unpurified silicon was leached out the impurity. Purification of this silicon was carried out two stages. The first stage, ten grams of the best results of the reduction process were put into beaker glass and added 100 $\mathrm{mL} \mathrm{HCl} 3 \mathrm{~N}$. The solution were then heated at $60{ }^{\circ} \mathrm{C}$ while stirring with a magnetic stirrer for 1 hour after which the samples were cooled and filtered with filter paper so that solids were obtained and filtrate [10]. The solid was washed with distilled water to neutral $\mathrm{pH}$ and then dried and weighed. The second stage of leaching, the first stage solid were put into the beaker glass. Then $100 \mathrm{~mL}$ of HF $5 \mathrm{~N}$ and acetic acid $25 \%$ were mixed by stirring to pour into the beaker glass. The mixed solution was heated at $70{ }^{\circ} \mathrm{C}$ while stirring with a magnetic stirrer for 1 hour. The solution was cooled and filtered to separate solids and filtrate [25]. The solid was washed with distilled water until neutral $\mathrm{pH}$ and then dried. This method was repeated with other variables of acetic acid concentrations at $35 \%, 45 \%, 50 \%, 60 \%$ as modified of method to obtained purified silicon. The purified of silicon was analyzed by XRF instrument to find the yield of silicon.

\subsection{Calculation yield of $\mathrm{Si}$}

The calculation of silicon yield was referred to basic equation from [26]. This formula can be seen in the Eq. 4.

$$
\mathrm{Si}(\mathrm{wt} \%)=\frac{\mathrm{MW}_{\mathrm{Si}}}{\mathrm{MW}_{\mathrm{B}}} \times \mathrm{W}_{\mathrm{b}} \times \mathrm{W}_{\mathrm{ash}} \times \mathrm{W}_{\mathrm{lch}}
$$

Where, $M W_{\mathrm{B}}$ is molar weight of compound $\mathrm{B}(\mathrm{g} / \mathrm{mole}), M W_{\mathrm{Si}}$ is molar weight of silicon $(\mathrm{g} / \mathrm{mole}), W_{\mathrm{Si}}$ is weight percentage of silicon in ash which is determined by XRF (\%), $W_{\text {ash }}$ is weight percentage of ash (\%), $W_{\text {lch }}$ is weight percentage of biomass residue that remained after leaching $(\%), W_{\mathrm{B}}$ is weight percentage of $\mathrm{Si}$ in the from of compound $\mathrm{B}(\%)$.

\section{RESULTS AND DISCUSSION}

\subsection{Effect mole ratio of $\mathrm{Mg} / \mathrm{SiO}_{2}$ to Silicon yield}

The optimum condition of silica reduction can be determined from redacted $\mathrm{SiO}_{2}$ to Silicon. Based on the results of processed XRF data, the yield of silicon can be presented in the following graph.

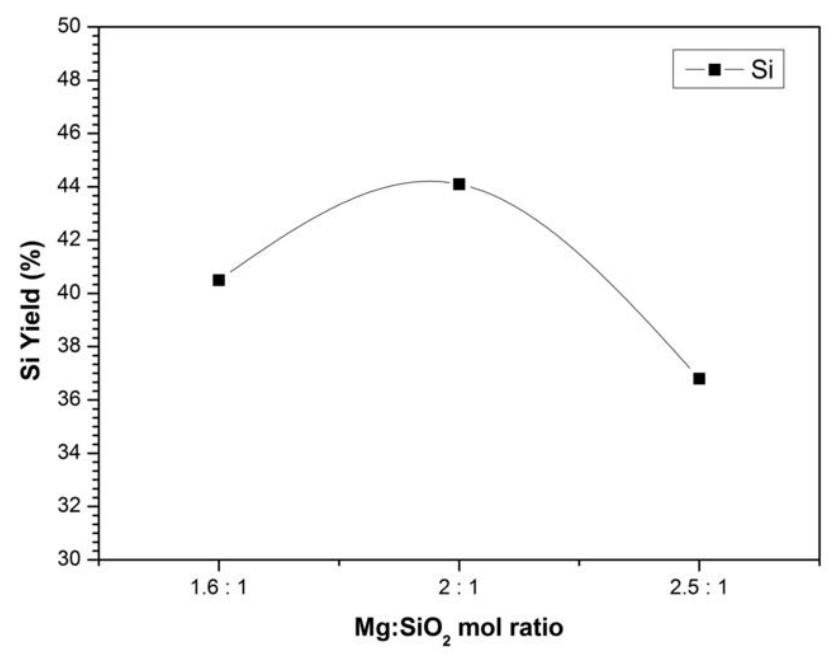

Figure 1: Effect of mole ratio of $\mathrm{Mg}$ to $\mathrm{SiO}_{2}$ on silicon yield at temperature $650{ }^{\circ} \mathrm{C}$, hold time $7 \mathrm{~h}$

As shown in Figure. 1, mole ratio of 2:1 of $\mathrm{Mg}: \mathrm{SiO}_{2}$ released the optimum yield of silicon. Silicon yield at a mole ratio of 2:1 was higher than that of 1.6: 1 . The yield of silicon reached the maximum ratio by increasing the mole ratio of magnesium/silica [25]. However, at a 2.5: 1 mole ratio the yield of silicon decreases. It was complied with [24] that increasing the relative molar ratio of $\mathrm{Mg}: \mathrm{SiO}_{2}$ above 2:1 stoichiometric level reduces silicon yield by increasing the formation of magnesium silicide $\left(\mathrm{Mg}_{2} \mathrm{Si}\right)$. The complexity of reduction mechanism involving gaseous and intermediate phase as $\mathrm{Mg}_{2} \mathrm{Si}$ considered to release $\mathrm{Si}, \mathrm{MgO}, \mathrm{Mg}_{2} \mathrm{Si}$, and $\mathrm{Mg}_{2} \mathrm{SiO}_{4}$ [10]. 


\subsection{Silicon recovery}

\section{Effect of hydrochloric acid leaching}

Leached silicon was analyzed by XRF analysis in order to measure the purity of silicon $(\% \mathrm{Si})$. Hydrochloric acid leaching was executed to dissolve $\mathrm{Mg}$ compounds in reaction products, i.e. $\mathrm{MgO}$ and $\mathrm{MgSi}[10]$. The results showed that acid leaching used $\mathrm{HCl} 3 \mathrm{~N}$ increased silicon purity. As the results (Figure. 1 and Figure. 2) show, the yield of silicon in the mole ratio of $2: 1$ before acid leaching achieved at $44.1 \%$. Post first acid leaching, the purity of silicon was obtained $77.1 \%$. The highest purity of silicon was attained by mole ratio of $\mathrm{Mg}$ to $\mathrm{SiO}_{2}$ at 2:1(Fig. 2).

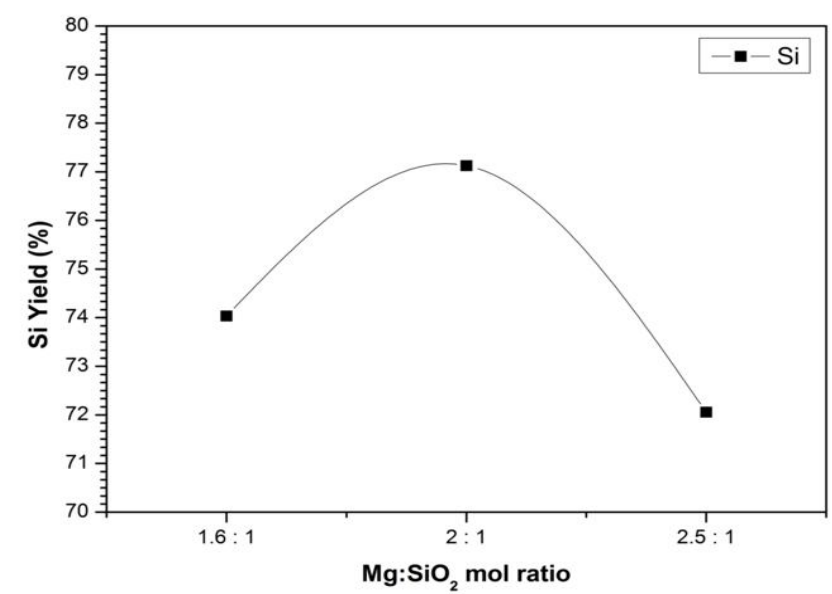

Figure 2: Effect of Hydrochloric Acid as first acid leaching to silicon yield at $3 \mathrm{~N}$

\section{Effect of hydrofluoric and acetic acid leaching}

Second leaching of silicon product from magnesiothermic reduction was also analyzed by XRF analysis. The mixture of acetic acid and hydrofluoric leaching was aimed to relieve other impurities. The impurities might be forsterite $\left(\mathrm{Mg}_{2} \mathrm{SiO}_{4}\right)$ and unreacted silica [10]. The highest purity of silicon was gained by mixture of $5 \mathrm{~N} \mathrm{HF}$ and $25 \mathrm{wt} \%$ $\mathrm{CH}_{3} \mathrm{COOH}$ acid leaching.

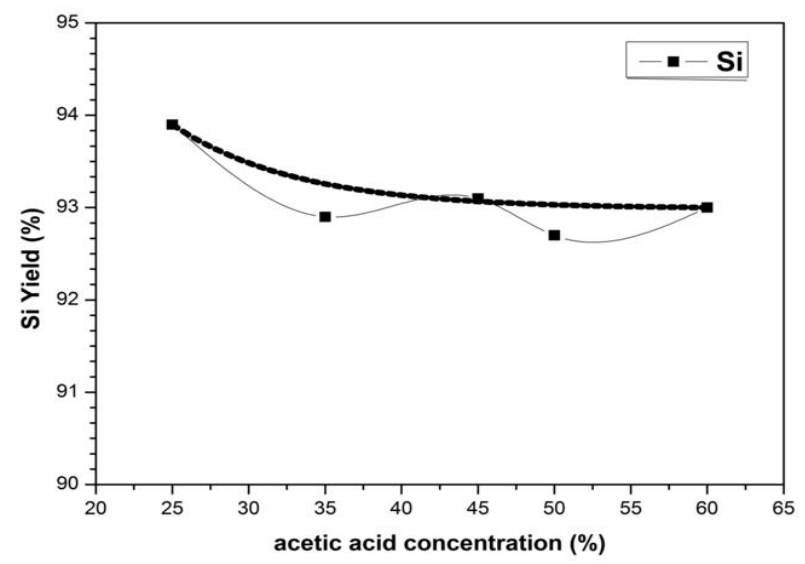

Figure 3: Effect acetic acid concentration on silicon purity
Figure. 3 shows that the increase in the concentration of acetic acid did not affect to the purity of the silicon. These results can be explained that the increase of acetic acid concentration should be followed by increasing in the concentration of HF [27]. In this study there were no increasing HF concentration as well as increasing acetic acid concentration. Therefore, the result visualized in Figure. 3 can be interred decreasing yield of silicon when increasing acetic acid concentration at constant HF concentration. The increasing HF concentration results increasing of $\mathrm{H}^{+}$and $\mathrm{F}^{-}$ions available to react with the mineral [28]. The leachant used is the mixture of HF and acetic acid. Acetic acid was added to function as a wetting agent during leaching processes. Acetic acid as wetting agent can relieve the surface tension of the mixture so that better wetting and a smoother etched surface results [29]. The increasing of wettability is allowing the infiltration of HF into the silicon pores [30]. Beside that, it was theorized that the wetting action of the acetic acid will prevents the formation of bubbles during etching [31]. Acetic acid serves as wetting agent generating $\mathrm{HF}$ in dissolving the impurities without difficulty and effectively due to reducing the surface tension.

\section{CONCLUSION}

Pure silica has been successfully purified from geothermal solid waste by silica gels and colloidal sols method and then converted into silicon by reduction processing using magnesium. Silica from geothermal solid waste prior to reduction with magnesium, the prepared silica derived geothermal silica acquired up to $96.6 \mathrm{wt} \%$. Magnesiothermic reduction at $650{ }^{\circ} \mathrm{C}$ and initial silicon recovery obtained the highest results at $\mathrm{Mg}: \mathrm{SiO}_{2}$ mole ratio of $2: 1$ and $3 \mathrm{~N} \mathrm{HCl}$ with yield of $77.1 \%$ and Si purity of $91.4-\%$ w. The Mg surplus can release side reactions reducing the yield of Si. That the increase of acetic acid concentration should be followed by increasing in the concentration of HF.

\section{ACKNOWLEDGEMENT}

The authors would like to show their gratitude for community of AMaL (Advanced Material Laboratory) at Departement of Chemical Engineering, Diponegoro University, Indonesia for all support and discussion throughout the research. This research was supported in part of Engineering Faculty Strategic Research 2019 under grant number 171/SK/UN7.3.3/V/2017.

\section{.REFERENCES}

1. Silviana, S., Hasbi, R. M., Sagita, C. P., Nurhayati, O. D., Fauzan, A., Suhartana, S., \& Hatmoko, J. U. D. (2017). Silika Alam dari Limbah Padatan Pengeboran Geotermal di Dieng sebagai Silika Gel Melalui Proses Ramah Lingkungan. Seminar Nasional Teknologo Hijau, 341-346. 
2. Chu, H., Wu, Q., \& Huang, J. (2018). Rice husk derived silicon/carbon and silica/carbon nanocomposites as anodic materials for lithium-ion batteries. Colloids and Surfaces A: Physicochemical and Engineering Aspects, 558, 495-503.

3. Jiang, Y., Zhang, Y., Yan, X., Tian, M., Xiao, W., \& Tang, H. (2017). A sustainable route from fly ash to silicon nanorods for high performance lithium ion batteries. Chemical Engineering Journal, 330, 1052-1059.

4. Silviana, S., \& Bayu, W. J. (2018). Silicon Conversion from Bamboo Leaf Silica By Magnesiothermic Reduction for Development of Li-ion Baterry Anode. In MATEC Web of Conferences (Vol. 156, p. 05021). EDP Sciences.

5. Perdigoto, M. L. N., Martins, R. C., Rocha, N., Quina, M. J., Gando-Ferreira, L., Patricio, R., Duraes, L., 2012. Application of Hydrophobic Silica Based Aerogels and Xerogels for Removal of Toxic Organic Compounds from Aqueous Solutions. Journal of Colloid and Interface Science, Volume 380, pp. 134-140.

6. Lee, J. A., Kim, M. K., Song, J. H., Jo, M. R., Yu, J., Kim, K. M., ... \& Choi, S. J. (2017). Biokinetics of food additive silica nanoparticles and their interactions with food components. Colloids and Surfaces B: Biointerfaces, 150, 384-392.

7. Frías, M., Savastano, H., Villar, E., Rojas, M., Isabel S. de, Santos, S., 2012. Characterization and Properties of Blended Cement Matrices Containing Activated Bamboo Leaf Wastes. Cement \& Concrete Composites 34, pp. 1019-1023.

8. Setyawan, H., Yuwana, M., \& Balgis, R. (2015). PEG-templated mesoporous silicas using silicate precursor and their applications in desiccant dehumidification cooling systems. Microporous and Mesoporous Materials, 218, 95-100.

9. Lin, N., Han, Y., Zhou, J., Zhang, K., Xu, T., Zhu, Y., \& Qian, Y., (2015). A low temperature molten salt process for aluminothermic reduction of silicon oxides to crystalline $\mathrm{Si}$ for Li-ion batteries. Energy \& Enviromental Science, 8(11), 3187-3191.

10. Barati, M., Sarder, S., McLean, A., Roy, R., 2011. Recovery of Silicon from Silica Fume. Journal of Non-Crystalline Solids, Volume 357, pp. 18-23.

11. Hatchard, T. D., \& Dahn, J. R. (2004). In situ XRD and electrochemical study of the reaction of lithium with amorphous silicon. Journal of the Electrochemical Society, 151(6), A838-A842.

12. Liu, N., Huo, K., McDowell, M. T., Zhao, J., \& Cui, Y. (2013), Rice husks as a sustainable source of nanostructured silicon for high performance $\mathrm{Li}$-ion battery anodes. Scientific Reports, 3, 1-7.

13. Wang, J., Li, S., Zhao, Y., Shi, J., Lv, L., Wang, H., ... \& Feng, W. (2018). The influence of different Si: C ratios on the electrochemical performance of silicon/carbon layered film anodes for lithium-ion batteries. $R S C$ Advances, 8(12), 6660-6666.

14. Salah, M., Murphy, P., Hall, C., Francis, C., Kerr, R., \& Fabretto, M. (2019). Pure silicon thin-film anodes for lithium-ion batteries: A review. Journal of Power Sources, 414, 48-67. https://doi.org/10.1016/j.jpowsour.2018.12.068

15. Wagner, R., Preschitschek, N., Passerini, S., Leker, J., \& winter, M. (2013). Current research trends and prospects among the various materials and designs used in lithium-based batteries. Journal of Applied Electrochemistry, 43(5), 481-496.

16. Son, B.D., Lee, J.K., Yoon, W.Y. (2018). Effect of tungsten nanolayer coating on $\mathrm{Si}$ electrode in lithium-ion battery, Nanoscale Research Letters 13 (58), 1-7.

17. Boussaa, S. A., Kheloufi, A., Zaourar, N. B., \& Bouachma, S. (2017). Iron and Aluminium Removal from Algerian Silica Sand by Acid Leaching. Acta Physica Polonica, A., 132(3).

18. Ugheoke, I. B. \&Mamat, O., 2012. A Critical Assessment and New Research Directions of Rice Husk. Maejo International Journal of Science and Technology, Volume 6(03), pp. 430-448.

19. Bao, Z., Weatherspoon, Michael R., Shian, S., Cai, Y., Graham, Phillip D., Allan, Shawn M., Ahmad, G., Dickerson, Matthew B., Church, Benjamin C., Kan, Zhitao, III, Harry W. A., Summers, Christopher J., Liu, M., Sandhage, Kenneth H., 2007. Chemical Reduction of Three-Dimensional Silica Micro-Assemblies into Microporous Silicon Replicas. Nature, 446, 172-175.

20. Sadique, S. (2010). Production and Purification of Silicon by Magnesiothermic Reduction of Silica Fume (Doctoral dissertation).

21. Jia, H., Gao, P., Yang, J., Wang, J., Nuli, Y., \& Yang, Z. (2011). Novel Three $\square$ Dimensional Mesoporous Silicon for High Power Lithium $\square$ Ion Battery Anode Material. Advanced Energy Materials, 1(6), 1036-1039.

22. Muda, M. F., Ahmad, S. W., Muftah, F., \& Sani, M. S. H. M. (2019). Mechanical Behaviour of Mortar Made with Washed Bottom Ash as Sand Replacement. International Journal of Emerging Trends in Engineering Research, 7(9), 7-14. https://doi.org/10.30534/ijeter/2019/09792019

23. E. A. Igwe. (2015) Comparative study on the effect of some non bituminous modifiers on HMA concrete stiffness modulus: study on optimal performance for heavy traffic, International Journal of Emerging Trends in Engineering Research, 3(9), 77-85.

24. Entwistle, J., Rennie, A., \& Patwardhan, S. (2018). A review of magnesiothermic reduction of silica to porous silicon for lithium-ion battery applications and beyond. Journal of Materials Chemistry A, 6(38), 18344-18356.

25. Larbi, K. K., Barati, M., \& McLean, A. (2011). Reduction behaviour of rice husk ash for preparation 
of high purity silicon. Canadian Metallurgical Quarterly, 50(4), 341-349.

26. Kow, K.-W., Yusoffa, R., Aziza, A. A., Abdullah, E., 2014. Physicochemical Properties of Bamboo Leaf Aerogels Synthesized Viadifferent Modes of Gelation. Applied Surface Science 301, p. 161-172.

27. Lu, H., Wei, K., Ma, W., Xie, K., Wu, J., Lei, Y., \& Dai, Y. (2017). Effect of acetic acid on the leaching behavior of impurities in metallurgical grade silicon. Separation Science and Technology, 52(7), 1257-1264.

28. Rodriguez, M. H., Rosales, G. D., Pinna, E. G., Suarez, D. S., 2015. Extraction of Niobium and Tatalum from Ferrocolumbite by Hydrofluoric Acid Pressure Leaching. Hydrometallurgy, Issue 156, pp. 17-20.

29. Shih, S., Jung, K. H., Hsieh, T. Y., Sarathy, J., Campbell, J. C., 1992. Photoluminescence and Formation Mechanism of Chemically Etched Silicon. Applied Physics Letters, Issue 60, p. 15.

30. Liu, X., Coxon, O. R., Peters, M., Hoex, B., Cole, J. M., Fray, D. J.., 2014. Black Silicon: Fabrication Methods, Properties and Solar Energy Applications. Energy \& Environmental Science.

31. Jenkins, M. W., 1977. A New Preferential Etch for Defects in Silicon Crystals. J. Electrochem. Soc.: Solid-State Science and Technology, 124(5).

https://doi.org/10.1149/1.2133401 